\title{
The development of simulation logic model that dealing with uncertainty for piping construction industry
}

\author{
Zirawani Baharum ${ }^{1}$, HairulNizam Mahdin², Fauziah Abdul Rahman ${ }^{3}$ \\ ${ }^{1,3}$ Malaysian Institute of Industrial Technology, Universiti Kuala Lumpur, Malaysia \\ ${ }^{2}$ Faculty of Computer Science and Information Technology, Universiti Tun Hussein Onn Malaysia, Malaysia
}

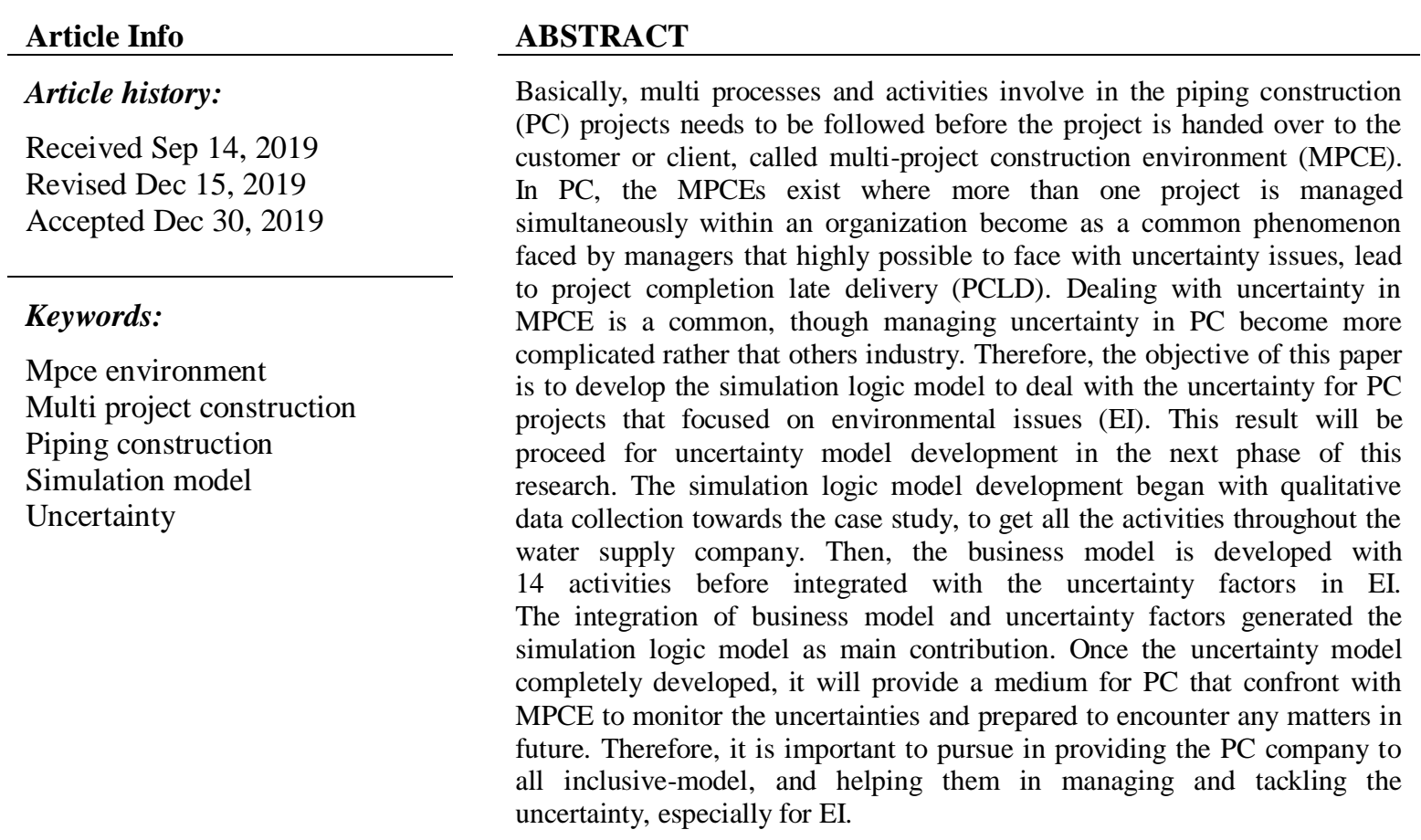

\section{Corresponding Author:}

Zirawani Baharum,

Malaysian Institute of Industrial Technology,

Universiti Kuala Lumpur, Persiaran Sinaran Ilmu,

Bandar Seri Alam, 81750 Johor Bahru, Malaysia.

Email: zirawani@unikl.edu.my

\section{INTRODUCTION}

Piping construction (PC) is a part of construction industry that plays an important role in any country's development process. It is both growth-initiating and growth dependent; includes in Malaysia. In architecture's project and civil engineering point of view, construction is the building or assembly of any infrastructure on a site or [1]. Although this may be thought of as a single activity, in fact construction is a feat of multitasking. Basically, there are several processes and activities involve in the construction projects that has been followed before the project is handed over to the customer or client. Following are several activities in the construction project of water supply piping, which are site clearance, excavation, deliver pipe, lay pipe, filling, deliver valve, lay valve, metalled road, fitting and special, testing (first testing), tapping, stand meter, connecting to existing pipe, concrete works, verification and validation (second testing), 
modification, miscellaneous, commissioning and tidy up and hand over. This process will become the fundamental steps to contractors and some of them might do modification to complement their project development and environment.

Likewise, the process can also be customised according to their environment and the numbers of project, known as multiple project construction environment (MPCE). The MPCE are also might be operated simultaneously. In PC, the MPCEs exist where more than one project is managed simultaneously [2] within an organization become as a common phenomenon faced by managers in construction organizations. This MPCE has become ubiquitous, and it is expected that multi-projects under a single company or management will deliver benefit which is not achievable if the projects were manage independently.

The nature of business is also studied to acquire the details activities involved in this PC. In general, project planner will get materials for construction directed from supplier or produce all the parts by themselves. This is means PC might be integrates with manufacture industry, which in some of construction companies they are able to constructing and manufacture. The typical structure for this business needs to takes number of projects to award the tender and averagely about seven to ten projects running simultaneously, that also called as MPCE, creates the uncertainty condition in their PC activities that lead to late project completion. Thus, dealing with uncertainty in MPCE and managing uncertainty in PC projects become more complicated rather that others industry. Therefore, the objective of this paper is to develop the simulation logic model to deal with the uncertainty for PC projects that focused on environmental issues (EI).

\section{MULTI PROJECT CONSTRCUTION ENVIRONMENT}

Most of water supply projects (piping construction) includes Syarikat Air Johor Sdn. Bhd. (SAJ) exist as part of a MPCE, where the management of multiple projects presents challenges that are fundamentally different from single project management. SAJ is one of the largest organisation involves in piping construction development in Malaysia as a business in supplying water to residents and other businesses. Their businesses are involving works of construction, maintenance and material supplies. Organisations are taking the MPCE initiative as efficient instrument to successful deliver improvements and change due to its unpredictable economic [3] is shifted into the multiple projects management.

Figure 1 shows the piping construction flow chart of project completion late delivery with MPCE for typical piping construction industry. The advantages of using this technique in the process of understanding the whole characteristics in the businesses as discussed previously. There are two levels constructed by system of flowcharting at outer level and inner level. From the investigation, two levels of the business model are charted out to show the underlying uncertainty of the activities while piping construction project is on the trail that sometimes called as level zero and level one. The flowchart shows that at outer level, the activities will have to consider all the uncertainties that might occur on each activities or processes in the project track. The uncertainty is only located at certain activity because some of the activities are dealt simultaneously. For example, when pipe and valve is attained and checked by supervisor, the pipe or valve can also immediately lay into the ground, even though sometimes they still need to work across, separately. It will depend on the size of PC projects and the materials availability. The activity in the flowchart at inner level will involve the details of uncertainty by considering all categories of causes to late delivery.

Uncertainty was a common terms of issues in each industry since past decades in many types, causes, with many reasons and aspects. It occurs without specific field of the industries either in large, medium or small enterprise (SMEs). There is no choice to ignore the uncertainties, except reducing, managing and tackling the problems with details investigation such as diagnosing and analysing the causes and effects uniquely to one industry. It is a very crucial for company to achieve high customer satisfaction preventing the bad-performance in late delivery. Plus, they have to strive with many issues and causes that can lead to potentially loss in profits [4] become as non-achievement in their quality performances. For example issues in safety matters as accidental on-site that predominantly contributed by environmental situation such as raining. And over, the piping project might be late to deliver because of flood causes from environmental seasons, the raining.

The uncertainty in PC field is investigated in this research. In PC, uncertainty also can be referred as complexity and risky of environmental. Report meeting ministry of Climate and Energy, Geological Survey of Denmark and Greenland has discussed five types of uncertainties, which are statistical, scenario, qualitative; recognise ignorance and epistemic arrogance [5]. Many issues appear and many researchers were trying to solve the problem since many of years. Most researchers [6-8] do their research by reducing uncertainty in limited issues, scope, constraints, and field of the companies, whereas they were ignored the uncertainty cause by environmental issues. 


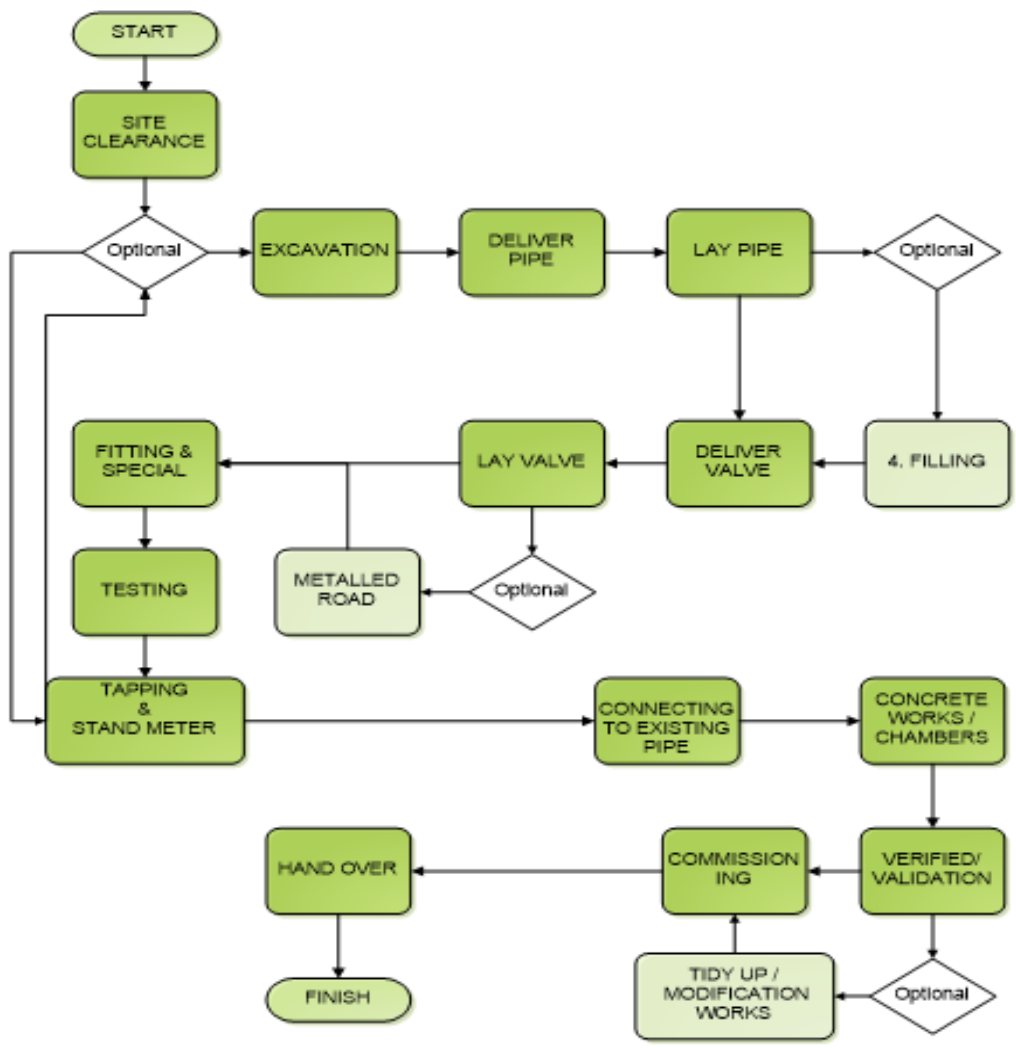

Figure 1. The business process flows in piping construction with MPCE

However, the successful of execution of MPCE is subject to considerable on the approach that the person manages uncertainties (such as uncertainty in environmental issues like unpredictable weather, accident and land structure difficulties) that may lead to schedule disruptions. The unpredictability of the current economic climate has directed the development of MPCE for PC. The research evidence to date has relied heavily on complexity in managing multiple projects that cause challenges in management $[9,10]$ such as uncertainty. Complexity of uncertainty is not necessarily a new challenge, but an old challenge that is being increasingly recognised and accepted as a key to improving performance and understanding of management [10].

Multiple projects management is faced with more challenges than single project management due to the complexity of the environment and organisations related to processes and project lifecycle. The complexity arises from interdependence and uncertainty in management which is the most critical features of context in developing effectiveness in organisational management [11]. At this stage, project management practice in MPCEs has not adopted an explicit way to identify and select the right management style that cause many issues and challenges occurred unnoticed. This phenomenon is also recognized as uncertainty in project management for piping construction projects. Although studies in the MPCE have examined the development of effectiveness in management $[12,13]$, there has been lack of an extended study on the uncertainty factors that contribute on project completion late delivery (PCLD).

There are no specific ways to ignore uncertainties except by reducing, managing and tackling the problems from detailed investigation, such as diagnose and analyse the causes and effects. Frequently, the project will be planned, scheduled and organized using a Critical Path Method (CPM) [14, 15] and Program Evaluation Review Technique (PERT) [16, 17]. The project is planned with a simple computer software such as Primawera or Microsoft office package software such as Visio, Project and Excel [18]. As a conclusion, it is highlighted that to manage projects is not as easy as it can see. In fact, to manage them in multiple projects is eager to hindrance a full focus of person involves to ensure the successful of project development, which it's become as the challenges for PC. Therefore, manging the uncertainty that surrounds in most of activities in the PC projects is important to be investigated as well. In order to managing the uncertainty, the development of simulation logic model that dealing with those uncertainties must be developed to simulate and validate the significant factors that underlaying as uncertainty. 
The simulation logic model will begin with business model development as discuss on the next section. Future, the development of uncertainty model will purposed to develop. The model of uncertainty might be reduces this matters and solves all the issues afterward. To develop the model the research need to understand the uncertainty itself and the challenges faced as mentioned previously. The uncertainty issues and the impact of project completion performance are important to study to review the overall challenges in uncertainty.

\section{THE SIMULATION DESIGN AND DEVELOPMENT}

For many years, simulation has been used for the design and analysis of most of industrial fields included piping construction. Important part before simulation can be examined is the model design of simulation development. Responses from a survey are always subjected to certain degree of reliability. To increase the reliability of the results, simulation studies were carried out to validate the conceptual model to be acknowledged as appreciated model. There are many advantages of using simulation for process of modelling like computing costs might be reduced by microcomputers and engineering work-station without tested by actual system [19] and Improvements in simulation software have reduced model development time, thereby allowing for more timely constructing analyses [20]. Plus, time setting is controlled by analyser, whereby the unit of time is setting interpreting from their research consumptions [20, 21].

When dealing with larger and more complex construction activities, as refer to piping construction operations, which are more difficult to manage using traditional project management tools (such as Microsoft Excel and Primavera), computer simulation methods have been shown to be effective in designing, analysing and managing the construction process, regardless of the complexity size [19]. A simulation model can be built to describe the construction activities of a scope of ranging from large, complex industrial project to simple room of a small building. The model also may able to use in managing operation and do prediction and forecasting resources and time requirements during project's execution.

In comprehensively, various techniques and approaches use by many researchers in their research for managing the uncertainties either managing, monitoring or controlling. By these literatures, most of researchers [21-26] preferred to use modelling and simulation development to encounter; managing, monitoring and controlling their problems of uncertainties. The model verifies with various methods and techniques of analysis and finish up their research via model development, experiments and model analysis and validation. Rather than looking to the numerous of techniques used in managing the uncertainty, here is the important reason why this technique is chosen for this research.

\subsection{Business Model of PC}

The simulation logic model is begin with the development of business model as conducted through the case study. Summary from all the activities of project completion that face the uncertainty, general view of the PCLD has been compressed to make the model representable and understandable. From the complete investigation, there are 14 main activities of piping construction project as verified by project manager at Syarikat Air Johor Sdn. Bhd. (SAJ). As a result, the business model for PCLD is finalised and represented in the Figure 2. Optional chart showing that there are several activities that run according to the crucial condition only, for example activity of metalled road is only sorted out if the piping project is mounted diagonally across the road and the road has damage and needs reparation.

All these activities are also discussed in [20]. With that, there are stated 14 main activities in the PCLD that lead to simulation model development, which are site clearance, excavation, deliver pipe and lay pipe, filling, deliver valve and lay valve, metalled road, fitting and special, testing, tapping and stand meter, connecting, concrete works/chambers, verified/validation, commissioning, and tidy up before hand over.

\subsection{Simulation Logic Model}

A model of modelling and simulation has properties that represent the real-world cases, and these properties are selected and extracted from phenomena in the object world and it is able to predict and helping us in make a decision under risk and uncertainty. It is also supported by [27, 28]. This is means that, the modelling and simulation were observed facts and filtered by a theory to formulate a world which itself is complete in terms of the theory. Obviously, through the literature, it is substantiated that the simulation and modelling is not only popular but also prevalent to be practise amongst the researchers.

The development of simulation started by designation of logic model with uncertainties to be wellthought-out as discussed in previous topic; the business process. From the details of piping construction project illustrated, then the structure of uncertainty management has been developed to demonstrate the repetition of uncertainties that underlie the piping construction and it becomes more influential for MPCE surroundings. The simulation analysis will accomplish through the process of validation. The integration of 
business model and all significant factors of environmental issues that underlaying as uncertainty becomes a direction and guidance for the process of simulation as presented in Figure 3.

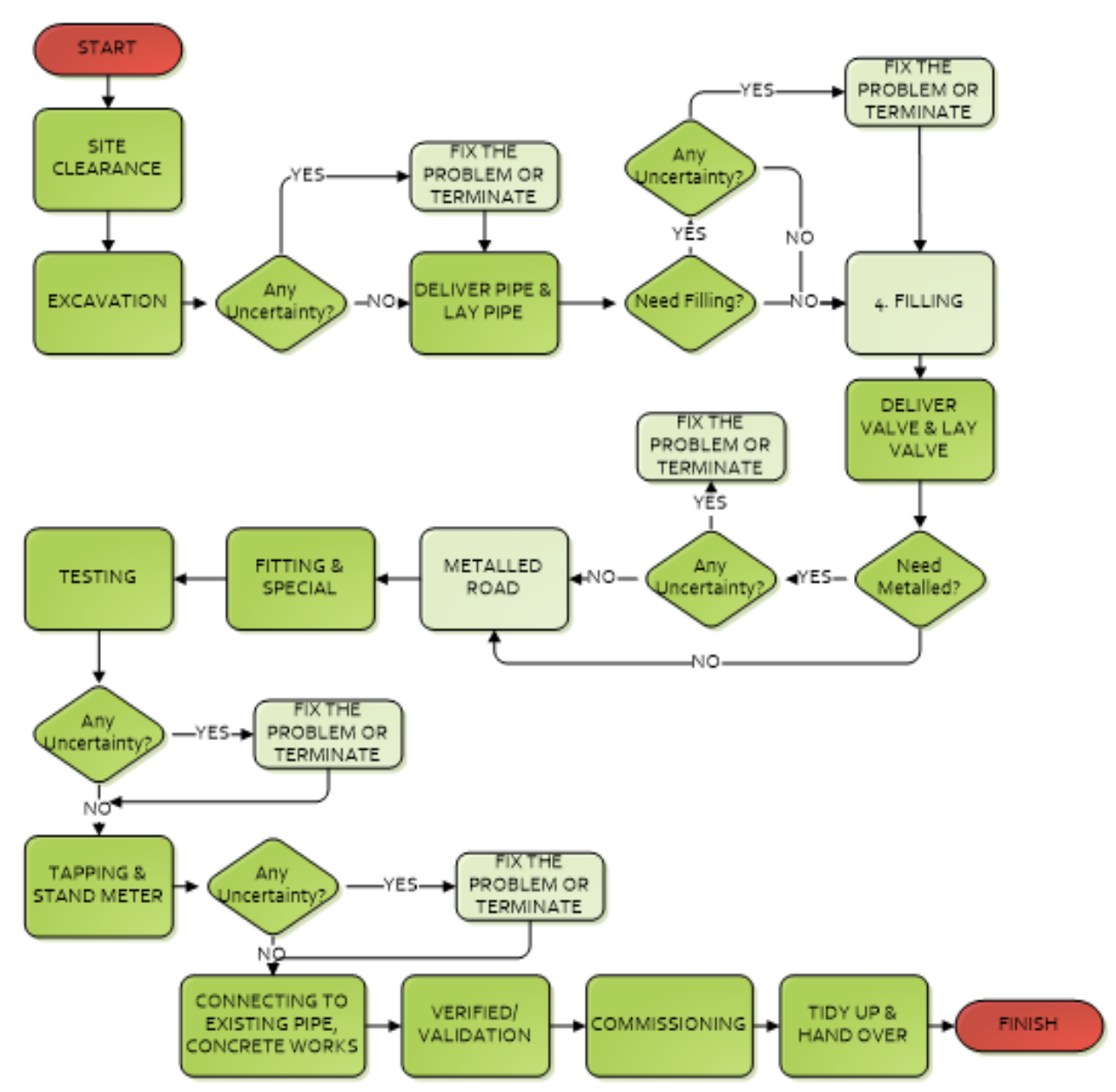

Figure 2. Business model on movement of goods in sea freight for simulation

The simulation logic model shows the structure flow to represents each activity in the business model to give a direction to the simulation and modelling for uncertainty with their condition and solution. It begins by looking over the project plan [29], which is first process of activity in the business process. At that point, the logic structure of simulation will examine either the uncertainties occur in that process or not. If there are uncertainties, the currents will one by one form at the type of uncertainty and take into account the circumstance if the uncertainty is not attempted. Neither the uncertainties are able to tackle nor may perhaps no uncertainty, the logic of structure endorse and frontward to the next process of activity.

The ultimate performance measure used is the proportion of PCLD in environmental issues, which is located at first level, namely level zero in the conceptual model. The figure also shows there are three strands namely unpredictable weather, land form structure and accident while construction, that is located at second level, called level one and afterwards. The reiterations will only discontinue after they were satisfied, which means no more process are remain to be performed or analysed. Three main types of uncertainty are unpredictable weather, soil condition and accident at sites. The underlying factors of uncertainty will be reiterated inside the main uncertainty. After the process of this iteration is finished, then the simulation system will guide the uncertainty factors to the next process to be appraised. 


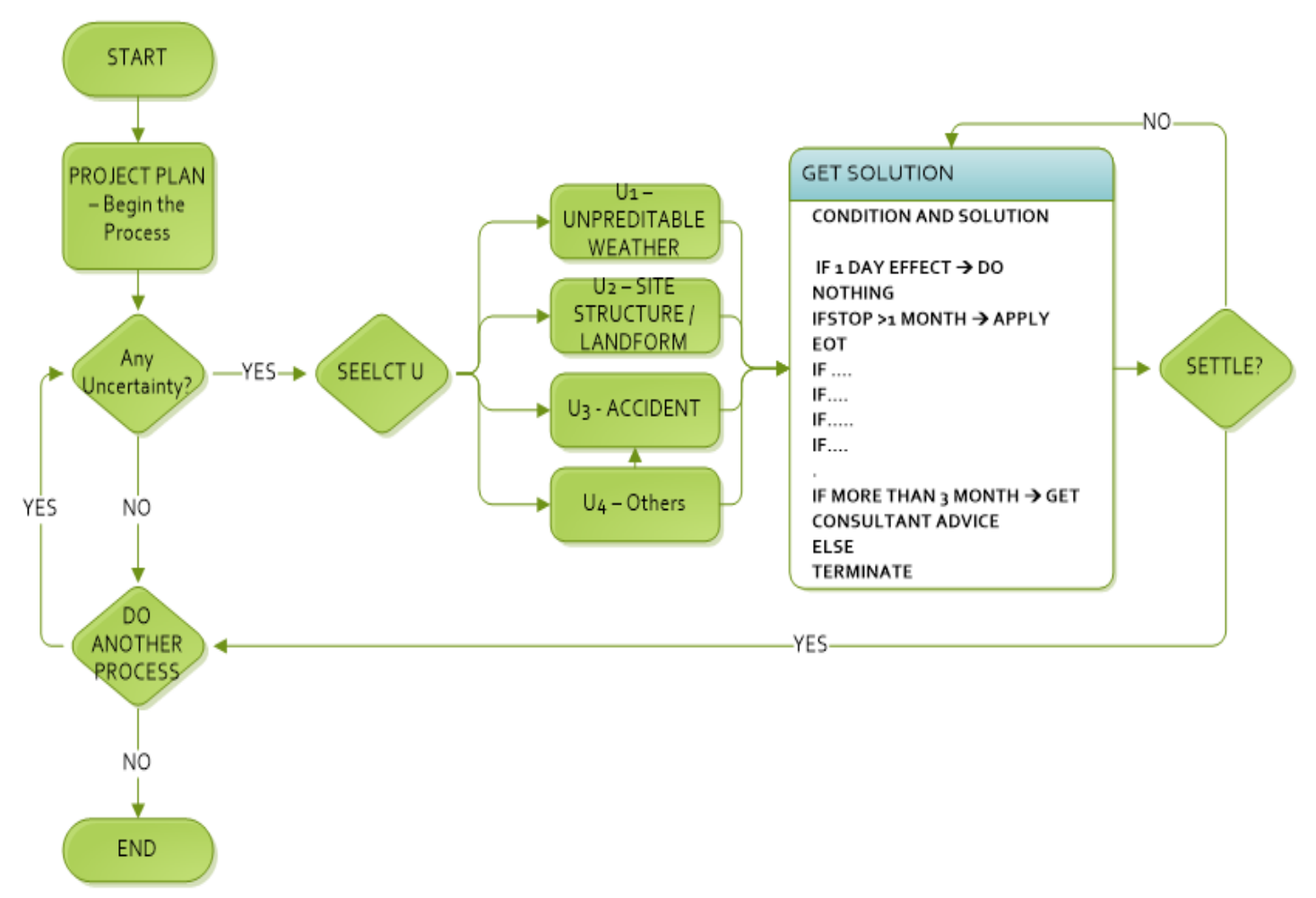

Figure 3. Simulation logic model for validation

\section{CONCLUSION AND FUTURE WORKS}

Many uncertainties in MPCE systems are treated as "controllable" elements, with a variety approaches being used to cope with them. However, modern PC has many underlying causes of uncertainty that impact on late delivery of project completion's performance, forcing enterprises into emergency measures to ensure delivery performance. In the present day dynamic market environment, meeting customer requirements is becoming increasingly important, especially in issues of delivery performance. The ability of industries to satisfy customer cravings in terms of delivery interval, project and product quality, are essential to stay in this kind of businesses. During the planning and construction progression, many uncertainties exist to which an enterprise must be able to respond even they are using MRP-controlled planning systems on that moment as suggested planners have to adjust the planning frequently. These dynamic necessities affect the efficient operation and progression of project completion.

Amongst the causes of uncertainty that are inspected within this research are about environmental issues, whereby it is included accidents, unpredictable weather and landform structure. Most of researcher they preferred to investigate the tangible causes of uncertainties especially material shortages, labour shortages, machine breakdown, scrap and rework. As pretty known, there are several issues in construction which one of them is bad quality in management that gives impact to construction schedule. Actually, there are no specific ways to ignore uncertainties except by reducing, managing and tackling the problems from detailed investigation, such as diagnose and analyse the causes and effects. The project would plan, schedule and organize using a CPM and PERT, while the project is plan with a simple computer software such as Primawera or Microsoft office package software such as Visio, Project and Excel. Uncertainty may always be a big reason for some of construction project late to deliver. Uncertainty can be resulted from lack of information or from disagreement. However, a project needs also to observer several imperceptible matters such as uncertainties to ensure the progression of PCLD is performing better than others. For that reason, the modelling of uncertainty possibly and logically to keep on developed in the way to prevent from too many sufferers and losers present in the middle of industry field. Consequential, well-managing and monitoring the model of uncertainty might be encountered off numerous complications such as un-satisfaction customers and in getting hold of high profits.

Through the investigation, 14 main activities of PC for water supply company are identified as discussed. With considered all the activities, the simulation logic model is developed to integrated with all significant factors of environmental issues that underlaying as uncertainty, accordingly. Purposely, 
this development contains the general view of PC that have been done by water supply company, SAJ focussed in the underlying factors of uncertainty in environmental issues. Likewise, PC will be able to deal with PCLD, through the development of simulation model.

The examination and analysis of the simulation model will be conducted in the next research-work in order to provide valuable data on the negative impacts of environmental issues factors towards MPCE project operations. The delay of piping installation activities can be significantly minimized. In future, the development of uncertainty model will be take part for validation process and the result will be evaluated. This model will provide a medium for PC that confront with MPCE to monitor the effects of the uncertainties and be more prepared to encounter them in future. Therefore, it is important to pursue this research, in providing the piping construction company on all inclusive-model, and helping them in managing and tackling the uncertainty, especially for open environmental (on-site environment) behaviours of PC that confront with highly risk of uncertainty factors in EI.

\section{ACKNOWLEDGEMENTS}

This work is supported by the Research and Innovation, Universiti Kuala Lumpur under the VOT: $\operatorname{str} 17034$

\section{REFERENCES}

[1] P. Ellenberger, (2014) "Piping and Pipeline Calculations Manual: Construction, Design Fabrication and Examination", Elsevier, Philadelphia, Pa, USA.

[2] Caniëls, M. C., \& Bakens, R. J. (2012). "The effects of Project Management Information Systems on decision making in a multi project environment”. International Journal of Project Management, 30 (2), 162-175.

[3] Hashim, N. I., Chilshe, N. and Baroudi, B. (2012) "Management challenges within multiple project environments: Lesson for developing countries", Australian Journal of Construction Economics and Building Conferences, Volume 1 (2) pp. 21-31.

[4] Pablo, B. P., Maria, L. C., Manuel, A. G. and Mari, C. G. (2015) "Climate and construction delays: Case study in Chile", Journal in Engineering, Construction and Architectural Management, Volume, 22 (6), pp. 596-621.

[5] Refsgaard, J. C. (2010) "Uncertainty and risk-terminology and concepts". CRES Annual Meeting, Geological Survey of Denmark and Greenland, Ministry of Climate and Energy, Svedberg.

[6] Alanjari, P., Asgarian, B. and Salari, N. (2014) "Elastic tubular joint element for modelling of multi-brace, uni-planar tubular connections", Journal in Ships and offshore, Volume 10 (4), pp. 404-415.

[7] Al-Buzz, W. W. and Mostafa, M. M. (2015) "Implementation of construction safety in reinforced concrete constructions executed by companies with moderate volume", International Journal of Research in Engineering and Technology, Volume 4 (4), pp. 202-206.

[8] Mehdi, T. (2011) "Development of Construction Projects Scheduling with Evolutionary Algorithms", Thesis report of Columbia University, New York, United States.

[9] Caniels, M. C. J. and Bakens, R. J. J. (2011) "The effects of project management information systems on decision making in a multi project environment", International Journal of Project Management, vol. 30 (2), pp. 162-175.

[10] Aritua, B., Smith, N. J. \& Bower, D. (2009) "Construction client multi-projects-A complex adaptive systems perspective", International Proceedings of the 2007 Winter Simulation Conference, pp. 1798-1804.

[11] Griffin, M. A., Neal, A. \& Parker, S. K. (2007) "A new model of work role performance: Positive behaviour in uncertain and interdependent contexts", Academy of Management Journal, Volume. 50 (2), pp. 327-347.

[12] Chinowsky, P S. and Songer, A. D. (2011) "Organization management in construction", Technology and Engineering, Routledge, Spon Press, Landon and New York.

[13] Patanakul, P. \& Milosevic, D. (2009) "The effectiveness in managing a group of multiple projects: Factors of influence and measurement criteria", International Journal of Project Management, Volume 27 (3), pp. 216-233.

[14] Mario, B., Damir, K. and Fertalj, K. (2012) "Resource constrained project scheduling under uncertainty: A survey", Central European Conference on Information and Intelligent Systems, Croatia, pp. 401-409.

[15] Wakas, S. K. and Leong, W. J. (2009) "Cost reduction for the project completion in shortest possible duration by stretching noncritical activities", Australian Journal of Basic and Applied Sciences, Volume 3 (4), pp. 4526-4533.

[16] Kuhl, M. and Tolentino, R. (2008) "A dynamic crashing method for project management using simulation-based optimization". Proceedings of the 2005 Winter Simulation Conference. pp. 1408-1412.

[17] Lu, M., and AbouRizk, S. M. (2000) "Simplified CPM/PERT simulation model". Journal of Construction Engineering and Management, Volume 126 (3), pp. 219-226.

[18] Li, H., Chan, N., Gu, H. L., Weisheng, L. and Skitmore, M. (2009) "Optimizing construction planning schedules by virtual prototyping enabled", Automation in Construction, Volume 18 (7), pp. 912-918.

[19] Labban, R., Abourizk, S., Haddad, Z. and Elsersy, A. (2013) "A discrete event simulation model of asphalt paving operations", Winter Simulation Conference, pp. 3215-3224.

[20] Zahran, H. and Nassar, K. (2013) "Modelling pipeline projects using computer simulation", Winter Simulation Conference, pp. 3269-3281. 
[21] Shahin, A., Abourizk, S. M., Mohamed, Y. and Fernando, S. (2013) "Simulation modelling of weather-sensitive tunnelling construction activities subject to cold weather", Canadian Journal in Civil Engineering, Volume 42 (1), pp.48-55.

[22] Mohd Yusof, E. M., Othman, M. S., Mi Yusuf, L., Raja Kumaran, S., and Mohd Yusof, A. R. (2019). "A model of acceptance factors for business intelligence in manufacturing using theoretical models". Indonesian Journal of Electrical Engineering and Computer Science (IJEECS), 14(3), 1544-1549.

[23] Chen, K., Lu, W. and Peng, Y. (2015) "Bridging BIM and building: From literature review to an integrated conceptual framework", International Journal of Project Management, Volume 33 (6), pp. 1405-1416.

[24] Mawlana, M. and Hammad, A. (2015) "Joint probability for evaluating the schedule and cost of stochastic simulation models", Journal of Advances Engineering Informatics, Volume 29 (3), pp. 380-395.

[25] G. Venille. "Simulation Analysis for Consistent Path Identification to Refine the Network Lifetime". Indonesian Journal of Electrical Engineering and Computer Science (IJEECS). 2017. 8(3): 674-678.

[26] EYazao Yang, Hailin Si, Xiaoni Hao, Junshao Luo. "Traffic Impact Simulation for Road Construction Project". TELKOMNIKA (Telecommunication, Computing, Electronics and Control). 2012. 10(8): 2176-2182.

[27] Etienne, D. R. (2012) "Modelling under risk and uncertainty: An introduction to statistical, phenomenological and computational methods", Books Series in Wiley Series in Probability and Statistics, John Wiley \& Sons, Ltd.

[28] Laurence, H. (2011) "Modelling human decision under risk and uncertainty", Thesis Dissertation of Wadham College, Oxford.

[29] M. M. Yusof, E., S. Othman, M., and M. Yusof, R. (2018). "Operational dashboard: Accelerator for shop floor workers”. International Journal of Engineering \& Technology, 7(2.29), 4-6.

\section{BIOGRAPHIES OF AUTHORS}
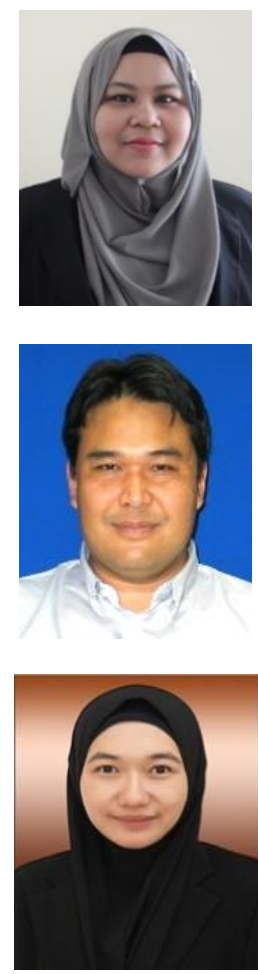

Zirawani Baharum finished her doctorates degree for Doctor of Philosophy in Computer Science in 2017. She received her B.Sc in Computer Science majoring in Modelling and Insudtrial Computing from Universiti Teknologi Malaysia (UTM), in 2003. Then, she received MSc in Information Technology from UTM in 2005. She received her Ph.D in Computer Science from UTM in 2017. She is currently a senior lecturer in Technical Foundation section, Universiti Kuala Lumpur, Malaysian Institute of Industrial Technology (UniKL MITEC). Her research interests are in thecomputer modelling and simulation, intergrted model development, computer science and information and communication technology (ICT).

Hairulnizam Mahdin is an Associate Professor at Department of Information Security and Web Technology, Faculty of Computer Science and Information Technology, Universiti Tun Hussein Onn Malaysia. He completed his Ph.D. thesis in 2012 and was conferred a doctorate degree from Deakin University Australia in the same year. His research focuses on the area of data management, IoT, RFID, information security, software engineering and web technology. He has published his research in both ISI and Scopus-indexed journals.

Fauziah Abdul Rahman received her B.Computer (Hons) in Business Information Technology from Coventry University, United Kingdom in 2000. She earned MSc in Information Technology from the Universiti Teknologi MARA. She is currently a lecturer in Technical Foundation Department at Universiti Kuala Lumpur, Malaysian Institute of Industrial Technology (UniKL-MITEC). Her research interests cover Business intelligence, Transportation Data Mining, Data Cleaning, Supply Chain Management System and Internet of Thing (IoT). 